\title{
SABER EL INFINITO. LEER A JUAN RAMÓN JIMÉNEZ EN UN PERMANENTE EJERCICIO DE INTERTEXTUALIDAD POÉTICA
}

JUAN L. DE LA CRUZ RAMOS

Universidad del País Vasco

juan.delacruz@ehu.es

«...la belleza huye de la vida de los

hombres hacia lo alto»

(Hölderlin, Hiperión)

«...ordeno

que por amor a mí no améis sino lo bello»

(Baudelaire, Spleen e ideal)

«Ahora, sé saludar a la belleza»

(Rimbaud, Una temporada en el infierno)

«...profundizar el fondo -hasta lo informe, hasta lo inexpresable puro...»

(Paul Valéry, Cuadernos)

«[Soy un hombre] consagrado a su trabajo y dedicado, tranquilo y tenaz, a transformar sus años en obras»

Stefan Zweig, El mundo de ayer 
Tal vez la fundamental labor del filósofo, no digamos del poeta, no sea hallar las contestaciones, sino empeñarse en plantear - plantearse- las vertiginosas preguntas. Las preguntas cortantes, filosas, las que arañan desasosegantes la piel, el corazón, el cerebro. Tal vez, corrido el tiempo, cuando el filósofo o el poeta o el poeta filósofo hayan coleccionado una teoría aplastante de preguntas -algunas nuevas, inveteradas la mayoría-, tal vez por algún resquicio se cuele el deslizante jirón de una respuesta. La resbaladiza pizca de una respuesta. En el mejor de los casos esta flaca exigüidad será el premio a una vida de investigación, de rastreo, de escritura.

Tal vez la fundamental labor del hombre pensante, del hombre sensible, no sea marcharse del laberinto, sino identificarlo. Encontrarlo. Saberse irremisiblemente perdido en él. Darse cuenta. Tal vez tras mucho, mucho tiempo de errar -equivocarse y vagar- tentando e intentando aberturas en el seto, ese hombre intuya alguna imposible salida. Cornelius Castoriadis, en Las encrucijadas del laberinto, dice que

pensar no es salir de la caverna, ni sustituir la incertidumbre de las sombras por los perfiles bien definidos de las cosas mismas, el resplandor vacilante de una llama por la luz del verdadero Sol. Es entrar en el laberinto. Es perderse en galerías que sólo existen porque nosotros las cavamos inteligiblemente, dar vueltas en el fondo de un callejón sin salida cuyo acceso se ha cerrado tras nuestros pasos - hasta que este girar abre, inexplicablemente, fisuras factibles en el muro- ${ }^{1}$

Junto al filósofo y al poeta, a una distancia aristocrática muchas veces no pretendida pero siempre inevitable, está el genio. Y ahí Juan Ramón Jiménez, que entró en el laberinto y no se perdió. Penetró el laberinto y llegó a comprenderlo. Vivió las preguntas y alcanzó, gozoso, trabajoso, las respuestas. La respuesta. Traspasó el muro hasta el otro costado.

En La insoportable levedad del ser Milan Kundera hace cierto que la misión del artista no es ni contar su propia vida ni crear algo estrictamente original o entretenido, sino intentar explicar, dar sentido a la compleja existencia humana a través de su obra. Para Juan Ramón Jiménez su Obra no fue una carrera ni una afición, sino una necesidad íntima y un acto de honestidad intelectual para con los demás. Ambas cosas. Juan Ramón Jiménez escribió por egoísmo y por humanismo. No sólo por egoísmo, aunque lo pareciera. No sólo por satisfacerse. Sino también, y muy acusadamente, por satisfacer al hombre -a todos los hombres dispuestos- alguna de las preguntas eternas. Y lo hizo al amor de la palabra, con el amor a la palabra bella. Con la palabra bella, que es amor. Para Juan Ramón escribir, escribirse, es una forma de amar. No necesita de la agresividad para su hondísimo estudio. Coincide así con Franz, el personaje novelístico que suavemente dice que «amar significa renunciar a la fuerza $»^{2}$. Con toda la fuerza de la palabra Juan Ramón llega hasta donde muy pocos. Juan Ramón, genio.

Juan Ramón humanista, al servicio del hombre. Sí, el Juan Ramón del ego inmenso, del yo irrefrenable, ese Juan Ramón está al servicio del hombre. Sin ninguna duda.

${ }^{1}$ Tomamos la cita de Cornelius Castoriadis, Figuras de lo pensable, Madrid, Cátedra/Universitat de València, 1999 , p.9

${ }^{2}$ Milan Kundera, La insoportable levedad del ser, Barcelona, Tusquets, 1985, p. 118 
Cuántas veces, frente a un Rubén Darío patético, a un Machado simpático y a un Lorca irresistiblemente carismático se nos abofetea con un Juan Ramón antipático. Es fácil, es verdad, sentir antipatía por el moguereño. Pero es sumamente empobrecedor instalarse en ella. Quedarse ahí. El misticismo juanramoniano suena arrogante pero, en realidad, no hay nada más humilde, porque implica poner lo grande aparte de sí mismo. En otro. Lo grande en dios. Lo grande es dios. No yo. Yo soy grande, muy grande, divino, no por ser Juan Ramón, sino porque dios está en mí. Y, mejor todavía: no soy grande por esto, sino por darme cuenta de esto. Por saber darme cuenta de esto. El yo juanramoniano que preña todos sus libros es un pronombre universal. Cualquiera es yo. Cualquier lector que quiera es yo. Que se atreva. Divino no es sólo Juan Ramón. Divino es cualquier hombre que le lea. Divino es cualquier hombre.

Juan Ramón no es un megalómano; no pretende suplantar a dios ni sustituirlo. Busca ansiosamente participar de él, tocarlo, fundirse en él. Alcanzar el éxtasis. En vida. Y lo logra. Y lo comparte con los demás hombres en su escritura. Anuncia a los demás hombres que es posible. Que se puede llegar. Que se puede ver la transparencia. Que el hombre, con mi poesía, puede:

Si el poeta (el hombre) se contenta con la realidad visible para su canto exaltado, no pasará de ahí, esa realidad en su vida. Si piensa y sueña y espresa otras realidades, las invisibles, que él clarivé, su espresión, su pensamiento, su sueño quizá las cuaje.

Este quizás es ya bastante para él. Y, en todo caso, el soñar, el pensar y el espresar una realidad invisible ¿no son una verdadera creación? ¿Vemos nosotros todo lo que la ciencia conoce de nuestro mundo? ¿Y por qué la Poesía que Platón señaló alada, graciosa, divina, ha de ir a la zaga de la ciencia? ${ }^{3}$

Como tantas veces en su exilio americano -como sabe cualquier experto los ejemplos podrían ser muchos- Juan Ramón ya no habla sólo desde sí mismo («yo») sino que se refiere también al otro («el hombre», «nosotros»). El camino metafísico que Juan Ramón recorre eminentemente pueden andarlo, también, los demás.

Insistir en la petulancia del egoísmo juanramoniano supone, amén de una lectura muy estrecha, reducir una obra máxima a una mínima anécdota. En el «Estudio preliminar» a Unidad, Diego Martínez Torrón subraya con enorme acierto que «se ha confundido esta preocupación por el Yo del hombre y por el Yo del poeta símbolo del hombre, con narcisismo. Lo cual no ha sido sino una lamentable trivialización y falseamiento del profundo pensamiento idealista de Juan Ramón» ${ }^{4}$. María Luisa Amigo y Emilio Ríos insistirán en que «éticamente, el poeta pretendió donar su experiencia a favor de sí mismo y de todos nosotros» ${ }^{5}$. El más profundo humanismo es, pues, una de las señas de identidad del de Moguer. Su generosidad. Su trabajar incansable por reconocer

\footnotetext{
${ }^{3}$ Juan Ramón Jiménez, Ideolojía (1897-1957) (Metamórfosis, IV), Barcelona, Anthropos, 1990, aforismo número 3249 (pertenece al Libro V de aforismos, escritos entre 1936 y 1949)

${ }^{4}$ Diego Martínez Torrón, «Estudio preliminar» a Juan Ramón Jiménez, Unidad, Barcelona, Seix Barral, 1999, p. 15

${ }^{5}$ María Luisa Amigo y Emilio Ríos, «Presentación» a Letras de Deusto, № 114 (Vol. 37), enero-marzo 2007, número homenaje a Juan Ramón Jiménez, p. 7. María Luisa Amigo, en su artículo «Experiencia de la belleza en Juan Ramón. Rasgos platónicos y superación del platonismo», remachará «la dimensión ética estética de su acción [se refiere, claro, a Juan Ramón], de su labor creadora y la donación que hará a la conciencia universal» (p. 60)
} 
-y en cierto sentido, conferir- al hombre su irrenunciable grandeza. Y ello en un siglo, el de la crisis del yo, en el que tantas ideologías reducían al ser humano a una miserable condición de número. Coincidimos por ello plenamente con Gilbert Azam cuando dice de Juan Ramón que

debemos concederle /.../ el mérito de haber instituido al hombre en un medio divino que viene a ser, en definitiva, su proyección en lo absoluto. Juan Ramón se identifica, asimismo, plenamente con su tiempo por esa forma de rechazar toda alienación, devolviendo a la condición humana su frágil y orgullosa grandeza. ${ }^{6}$

Juan Ramón Jiménez crea belleza que regala al hombre. Y le confía a éste que cuando la crea -o la lee- la belleza le diviniza. En ese instante, le diviniza. La capacidad estética es una virtud genuinamente humana que nos acerca a los dioses. Que nos hace dioses. Que nos hace radicalmente hombres. Juan Ramón sabía, como Schiller, que la belleza es la consumación de la humanidad ${ }^{7}$.

Puro humanismo, pues, el de nuestro Juan Ramón, que queda muy lejos de esa imagen egotista tan extendida. Así entendemos que el uno de febrero de 1953, en La Prensa de Nueva York, respondiendo a un cuestionario preparado por Juan Bertolí Rangel, afirmara tajante que «lo primero para mí en la vida es la humanidad circundante». Juan Ramón Jiménez, con su Obra, nos entrega «ese regalo mío único» que le ha costado tanto sacrificio, tanto y tanto trabajo; su bondad estriba en sacrificarse para crearlo y dárnoslo, regalárnoslo:

«De ese regalo mío único»

(poema de 1920)

¡Martirio de mi hoy, que has de dar, difícil, tanta belleza propia, mañana, a otros fácil!

¡Secreto poderoso y firme que otro podrá cojer lo mismo que una rosa que mil siglos han hecho breve y bella con sol y viento y agua y terremoto!

¡Goce, alegría inmensa de ese regalo mío único, bueno como de dios! ${ }^{9}$

\footnotetext{
${ }^{6}$ Gilbert Azam, La obra de Juan Ramón Jiménez. Continuidad y renovación de la poesía lírica española, Madrid, Editora Nacional, 1983, p. 637

${ }^{7}$ «La belleza como consumación de su humanidad...», escribirá Schiller en la Carta XV de sus Cartas sobre la educación estética del hombre, Buenos Aires, Aguilar, 1981, p. 89. En el mismo sentido, en la Carta XXI dirá: «...tenemos que considerar la capacidad que le ha devuelto a la disposición estética como el más alto de todos los dones, como el don de la humanidad» (p. 118)

${ }^{8}$ Citado por Ricardo Gullón, El último Juan Ramón Jiménez. Así se fueron los ríos, Madrid, Alfaguara, 1968, p. 112

${ }^{9}$ Unidad, op. cit. en N. 4, p. 113
} 
Al final de otro artículo que hace algún tiempo publicamos concluíamos -jugando con un muy famoso aforismo suyo- que Juan Ramón «es capaz ni más ni menos que de 'hacer fable lo inefable'. De hacerse afable» ${ }^{10}$. En efecto, a la inefabilidad dedicó por entero su vida. Su Obra. A decir todo aquello imposible que, si no se dijera, si no lo hubiera dicho, si no hubiera sabido decirlo, le habría dejado -y con él a la humanidad entera- incompleto. Juan Ramón sabía, como los simbolistas, que a la poesía y sólo a la poesía le está reservada la tarea de penetrar en lo inefable ${ }^{11}$. En tamaña labor se empeñó. Aun a riesgo de ser tildado de loco. En decirse y decirle al hombre -en decirnos, en definitiva- que por medio de la palabra poética se accede a la plenitud. Juan Ramón, para ser hombre cabal, por serlo, necesitaba de ésta; y es «esa avidez de eternidad [la] que, desde muy temprano, está en la base de su escritura $\rangle^{12}$. Él sabe radicalmente del poder de la palabra. De la fuerza de la palabra bella. De hasta dónde se puede ir con ella. «Haber sentido, pensado y espresado la Belleza es la mayor gloria y la mejor gracia del hombre, el más alto sentido de su vida y el más dulce descanso de su muerte» ${ }^{13}$.

Otros genios, pocos, son conscientes de esto. En su novela sobre la Belleza, en su novela de la Belleza, Thomas Mann le hace decir a Sócrates, o mejor, dice que Sócrates decía: «La Belleza es el camino del hombre sensible hacia el espíritu» ${ }^{14}$. Ése es también el descubrimiento de Juan Ramón. Ese descubrimiento suyo y su increíble facticidad, su increíble saber una y otra vez llevarlo a cabo, saber decirlo, hacen de él y de su Obra algo enorme. Se trata de una prodigiosa suerte de tautología: Juan Ramón descubre la divinidad dentro de sí porque descubre que puede decirla -la divinidad-gracias a la palabra bella, exacta, que es capaz de crear. Antonio Sánchez Romeralo lo resume muy atinadamente así:

... aparece ante su conciencia una triple revelación: que el vuelo del espíritu humano podía llegar a ser en sí divino; que el hacer humano reflejado en una obra podía también divinizar; y, por último, que el hombre podía conseguir la eternidad dentro del tiempo limitado de su existencia. $^{15}$

Nos interesa subrayar también, al hilo de la cita precedente, la palabra vuelo. En otro artículo que publicamos ${ }^{16}$ ya hablamos largo y tendido del vuelo juanramoniano. Nuestro autor, gracias a su literatura, se instala alto. Lejos. No se trata exactamente de una evasión física en el espacio-tiempo. Ni de una evasión más o menos bohemia a ningún paraíso artificial. Se trata de algo mucho más hondo, más grande: de un ascenso metafísico, estético,

\footnotetext{
${ }^{10}$ Juan L. de la Cruz Ramos, «Juan Ramón Jiménez. La poesía del entusiasmo» en Letras de Deusto, № 108 (Vol. 35), julio-septiembre 2005, p.43

${ }^{11}$ Cfr. Juan Ramón Jiménez, El trabajo gustoso, Madrid, Aguilar, 1961, p. 36

12 Javier Blasco, «Introducción» a Juan Ramón Jiménez, Antología poética, Madrid, Cátedra, 1990, 6ª ed., p. 81

${ }^{13}$ Lo escribe en 1938 en un texto titulado «La Belleza», publicado en Guerra en España (1936-1953), Barcelona, Seix Barral, 1985 (introducción, organización y notas de Ángel Crespo), p. 186

${ }^{14}$ Thomas Mann, Muerte en Venecia, Barcelona, Plaza y Janés, 1999, p. 75

${ }^{15}$ Antonio Sánchez Romeralo, «Juan Ramón Jiménez en su fondo de aire» (1961) en Aurora de Albornoz (Ed.), Juan Ramón Jiménez, Madrid, Taurus, 1981, p. 155. Un poco antes, en la misma página, Sánchez Romeralo dice: «El gran hallazgo se llama, una vez más, inmanencia. Para encontrar a dios no necesita salir de sí, sino buscarlo en su conciencia»

${ }^{16}$ Juan L. de la Cruz Ramos, «Juan Ramón Jiménez. La alta profundidad» en Letras de Deusto, № 114, op. cit. en N. 5, pp. 133-149
} 
místico, a la vida de arriba, a la alta profundidad. En la primera lira de su bellísimo poema «En la Ascensión», Fray Luis de León - a quien tanto leyera Juan Ramón- se queja:

¡Y dejas, Pastor santo, tu grey en este valle hondo, escuro, con soledad y llanto!

Y tú rompiendo el puro aire, ¿te vas al inmortal seguro ${ }^{17}$

Juan Ramón lo logra. Llega al inmortal seguro. Se eleva constantemente con sus versos. En sus versos. Juan Ramón ha nacido para un mundo profundamente elevado. Como Nietzsche. Aunque tan distintos -ateo éste, místico aquél- ambos son dos genios aristócratas de la Belleza. En Ecce Homo el alemán asegura que «quien sabe respirar el aire de mis escritos, sabe que es un aire de altura, un aire fuerte» ${ }^{18}$. Y también asegura que «yo vengo de alturas que ningún pájaro jamás ha volado, yo conozco abismos en los que aún no se ha extraviado pie alguno» ${ }^{19}$. Así también Juan Ramón. Entre tantos como podríamos elegir, el primer verso del poema número cuatro de la primera parte del libro Ellos, poema titulado «El mundo», publicado en 1922, exclama: «iGocémoslo, volando!» ${ }^{20}$. Siempre volando... Y es que Juan Ramón sabe, como 'Longino', que «lo sublime es como una elevación y una excelencia en el lenguaje» ${ }^{21}$; que «debemos, en la medida de lo posible, elevar nuestras almas hacia todo lo que sea grandioso, y preñarlas, por así decirlo, constantemente de nobles arrebatos» ${ }^{22}$. Juan Ramón sabe que

[los genios, los espíritus divinos] vieron, además de otras muchas cosas, esto: que la naturaleza no ha elegido al hombre para un género de vida bajo e innoble, sino que introduciéndonos en la vida y en el universo entero como en un gran festival, para que seamos espectadores de todas sus pruebas y ardientes competidores, hizo nacer en nuestras almas desde un principio un amor invencible por lo que es siempre grande y, en relación con nosotros, sobrenatural. Por esto, para el ímpetu de la contemplación y del pensamiento humano no es suficiente el universo entero, sino que con harta frecuencia nuestros pensamientos abandonan las fronteras del mundo que les rodea y, si uno pudiera mirar en derredor la vida y ver cuán gran participación tiene en todo lo extraordinario, lo grande y lo bello, sabría, en seguida, para qué hemos nacido. ${ }^{23}$

${ }^{17}$ Fray Luis de León, Poesía, Zaragoza, Editorial Ebro, 1980 (selección, estudio y notas de J. M. Alda Tesán), p. 72. En el Libro XI de El Paraíso perdido, de John Milton, dice Adán algo que nos recuerda a Fray Luis (y al «Salmo primero» bíblico y unamuniano): «...lo que más me aflige en la partida/ es que su faz quede para mí oculta/ y se me prive contemplar su rostro» (Madrid, Cátedra, 2001, 4ª ed., p. 310)

${ }^{18}$ Nietzsche, Ecce Homo, Buenos Aires, Losada, 2004, p. 26

${ }^{19}$ Ibídem, p. 80

${ }^{20}$ Juan Ramón Jiménez, Ellos. Libro inédito, Santiago de Compostela, Linteo, 2006 (edición, introducción y notas de José Antonio Expósito Hernández), p. 44

21 'Longino', Sobre lo sublime en Demetrio, Sobre el estilo / 'Longino', Sobre lo sublime, Madrid, Gredos, 1979, (introducción, traducción y notas de José García López), p. 148

${ }^{22}$ Ibídem, p. 160

${ }^{23}$ Ibídem, pp. 202-203 
Juan Ramón sabe, como el Maestro Eckhart, que «quien desea cosas elevadas, ése está elevado» ${ }^{24}$. Sabe, como Hölderlin, que «dejé esta tierra tan pequeña, emprendí vuelo hacia las estrellas» ${ }^{25}$. Sabe, como Stendhal, que «es por la costumbre de nutrir su alma de emocionantes sueños, y por su horror a lo vulgar, por lo que un gran artista está tan cerca del amor» ${ }^{26}$. Sabe, como Fernando Pessoa, que «todo se desplaza en lo alto» ${ }^{27}$... Juan Ramón, en definitiva, no es como el albatros baudelaireano, al que

exiliado en la tierra, sufriendo el griterío,

sus alas de gigante le impiden caminar. ${ }^{28}$

Juan Ramón, exiliado en el cielo, ajeno al griterío, vuela con sus alas de gigante... Por eso dirá en 1941: «¿Cómo podré ya querer otra cosa? Conciertos, libros, paseos, civilización, universalidad pero nada convencional, todo superior absoluto» ${ }^{29}$.

Juan Ramón Jiménez fue alguien extraordinario. Uno de esos pocos superdotados que iluminan la historia. Uno de esos pocos hacedores de Belleza que alcanza la certeza -instantánea, repetida- de la eternidad infinita. Un artista singular que quiso, supo y pudo acceder. Juan Ramón, es sabido, es el hombre tocado por una agudísima hipersensibilidad, gozosamente enfermo de hiperestesia. Le supongo formando parte de la élite que describiera Hume:

Hay gente que está sujeta a una cierta delicadeza de pasión, que les hace extremadamente sensibles a todos los accidentes de la vida ${ }^{30}$

Juan Ramón, a miles de millones de años luz de la vulgaridad, «siempre sin tiempo, chorreando belleza propia» ${ }^{31}$. Dueño de una prodigiosa capacidad de absoluto que le sube, constantemente le sube. Porque, como diría esta vez Addison, «el que posee una imaginación delicada, participa de muchos y grandes placeres, de que no

\footnotetext{
${ }^{24}$ Maestro Eckhart, El fruto de la nada y otros escritos, Madrid, Siruela, 2008, 6a ed., p. 149. De la serie «Proverbios y leyendas» número 20. Dice en número 18: «No os ocupéis de cosas pequeñas, pues no habéis sido creados para nada pequeño» (p. 148)

${ }^{25}$ Del borrador de una carta de Hölderlin, sin fecha. En Friedrich Hölderlin, Poemas de la Locura precedidos de algunos testimonios de sus contemporáneos sobre los «años oscuros» del poeta (edición bilingüe), Madrid, Hiperión/Peralta, 1979, $2^{a}$ ed. (traducción y notas de Txaro Santoro y José María Álvarez), p. 43. En la misma carta dice: «No solamente los males de la tierra me parecen pequeños y poco importantes; incluso sus alegrías no eran para mí más que golosinas hechas para niños y no para Dioses, y el hombre es un dios si quiere serlo» (p. 43). Y también dice: «No quiero caer de mi cielo» (p. 44)

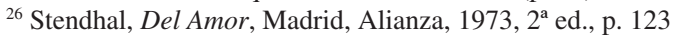

${ }^{27}$ Fernando Pessoa, Libro del desasosiego, Barcelona, Acantilado, 2003, $3^{\mathrm{a}}$ reimpr., p. 477. Tomado del fragmento 472

${ }^{28}$ Charles Baudelaire, Las flores del mal, Barcelona, Orbis/Origen, 1982, p. 18

${ }^{29}$ Juan Ramón Jiménez, Tiempo, Barcelona, Seix Barral, 2001, p. 74

${ }^{30}$ David Hume, «Sobre la delicadeza del gusto y de la pasión» en La norma del gusto y otros ensayos, Barcelona, Península, 1989, p. 53

${ }^{31}$ Juan Ramón Jiménez, «El andaluz universal. Autorretraro (para uso de reptiles de varia categoría)» (1923) en Españoles de tres mundos, Madrid, Alianza, 1987 (introducción y edición de Ricardo Gullón), p. 212
} 
puede disfrutar un hombre vulgar» ${ }^{32}$. Juan Ramón fue ese hombre señero, elegido, con una especie de «excitabilidad del alma, por así decirlo»-recurrimos ahora a Kant ${ }^{33}$ que le permitió bucear hasta el suelo marino de los versos.

Es fácil confundir con locura su genialidad. Claro que ya Petrarca, en el libro tercero de Secreto mío, nos recuerda «las palabras de Platón - 'en vano llama a las puertas de la poesía quien está en sus cabales'- y las de su sucesor Aristóteles -'ningún ingenio grande sin mezcla de locura'-...»

Es fácil confundir con locura la genialidad de Juan Ramón, decimos. Su excepcionalidad. Una excepcionalidad gracias a la cual cautivó a muchos de sus contemporáneos. Y que hoy sigue, huelga decirlo, fascinando. Fascinándonos. Cuenta graciosamente Carmen Conde cómo muchos poetas jóvenes de los años veinte y treinta estaban «juanramonizados» ${ }^{35}$... Nuestro moguereño fue un gran hombre, sin duda. Supo dialogar con el misterio y penetrarlo. Supo ir más allá. Supo estar radicalmente insatisfecho con lo de aquí abajo. Parece como que Leonardo Boff pensara en él cuando escribiera que «el ser humano es trascendencia, y por eso viola todos los tabúes, traspasa todas las barreras y no se contenta más que con el infinito» ${ }^{36}$. Sólo con el infinito se contentó Juan Ramón. Para lograrlo necesitó de su reclamado silencio y de su fecunda soledad. De un retiro obsesivo, maniático, que le llevó a mudarse -ipobre Zenobia!- incontables veces en busca de su necesario apartamiento. Apartamiento, en realidad, como nos recuerda Octavio Paz en su prólogo de 1962 al Árbol de Diana de Alejandra Pizarnik, imprescindible para poder ver la transparencia:

Durante mucho tiempo se negó la realidad física del árbol de Diana. En efecto, debido a su extraordinaria transparencia, pocos pueden verlo. Soledad, concentración y un afinamiento general de la sensibilidad son requisitos indispensables para la visión. ${ }^{37}$

La manía solitaria, la manía de la soledad, no es, pues, una capricho juanramoniano. Ni exclusiva de él. Sino derecho de todos cuantos quieran -los pocos que pueden- hacerse con lo invisible. Es cierto que su afán de retiro le granjeó esa fama de huraño que le acompañará para siempre. Le granjeó esa fama de querer establecerse, aislarse en su tantas veces repetida torre de marfil. Es cierto eso. Pero el aislacionismo juanramoniano - probablemente enfermizo- tiene sentido. Y lo tiene porque le resulta efectivo. Es inmensamente fecundo. Juan Ramón escribe y escribe y corri-

\footnotetext{
32 Joseph Addison, «Ensayo sobre los placeres de la imaginación» en Los placeres de la imaginación (y otros ensayos de «The Spectator»), Madrid, Visor, 1991, p. 134. Un poco más adelante insiste: «nada hay que más directamente camine al alma que la belleza» (p. 141)

${ }^{33}$ Inmanuel Kant, Observaciones acerca del sentimiento de lo bello y lo sublime, Madrid, Alianza, 2008, p. 30

${ }^{34}$ Petrarca, Obras I. Prosa, Madrid, Alfaguara, 1978, p. 121

${ }^{35}$ Carmen Conde, «Encuentros con Juan Ramón Jiménez» (1974) en Aurora de Albornoz (Ed.), op. cit. en N. 15 , p. 39

${ }^{36}$ Leonardo Boff, El cuidado esencial. Ética de lo humano, compasión por la tierra, Madrid, Trotta, 2002, p. 155

${ }^{37}$ Octavio Paz en Alejandra Pizarnik, Poesía Completa, Barcelona, Lumen, 2003, 6 a ed., p. 102
} 
ge y corrige en su fertilísimo encierro. Para él, soledad es trabajo. Nunca holganza. La necesita porque, como dice hermosamente en carta a Rubén Darío, «la soledad es buena amiga de la bondad y de la belleza» ${ }^{38}$.

Desde esa mendigada soledad física e intelectual que contribuye no poco a su fama de raro, de loco, es desde donde consigue, como venimos diciendo, acceder a lo invisible. Desde la palabra exacta que alcanza en su solitario trabajar. Como diría Francisco Javier Blasco Pascual, Juan Ramón llegó a ser un supervisor, el poeta capaz de ver lo imposible, de aprehender lo que sólo alguien como él tenía la habilidad poética de aprehender:

En el marco del romanticismo afloran una serie de dicotomías cuya vitalidad en la poesía posterior es indudable. Materia y espíritu, lo conocido y lo desconocido, realidad interior y realidad exterior, son algunos de los términos en que se plasma la visión dualista del universo romántico. Para los simbolistas, sin embargo, la unidad es posible, ya que, entre la realidad interior y la realidad exterior, entre materia y espíritu, entre lo conocido y lo desconocido, existen pluralidad de «correspondencias», que el arte puede reconstruir y hacer patentes. El arte potencia el paso de lo conocido a lo desconocido y hace posible el salto de la realidad visible a la realidad invisible. Es éste, sucintamente esquematizado, el mismo clima que emana la poética juanramoniana. ${ }^{39}$

El instrumento juanramoniano es, pues, la poesía. Utilizará la prosa para otros menesteres. La poesía es para lo vertical y la prosa para lo horizontal. «La poesía auténtica nunca podrá ser horizontal. Eso es propio de la prosa $»^{40}$. Juan Ramón hace verdaderas como pocos las palabras de Lewis:

...la poesía moderna, si algo «dice», si, además de «ser», aspira a «significar», dice algo que la prosa no podría decir en modo alguno. / . . / La poesía es hoy mucho más quintaesencialmente poética que en cualquier otra época. Es «más pura» /.../. No sólo hace (como toda buena poesía) lo que la prosa es incapaz de hacer, sino que evita deliberadamente hacer cualquier cosa que ésta pueda hacer. ${ }^{41}$

Juan Ramón sabe como casi nadie de la potencia de la palabra poética. Y sabe como nadie de la potencia de su palabra poética. Prácticamente nunca incurre en falsa modestia. Eso no va con él. Se sabe grande. Se sabe genio. Françoise Pechère y su hija, Gazou, fueron amigas y asiduas visitantes de Juan Ramón y Zenobia mientras éstos vi-

${ }^{38}$ Juan Ramón Jiménez, Cartas, Madrid, Aguilar, 1962 (edición de Francisco Garfias), p. 41

${ }^{39}$ Francisco Javier Blasco Pascual, La Poética de Juan Ramón Jiménez. Desarrollo, Contexto y Sistema, Salamanca, Universidad de Salamanca, 1982, p. 227. Más adelante insiste: «...la poesía se ofrece como una forma de conocimiento no conceptual /.../. Desde el romanticismo, se ve en la poesía la solución a dicho problema: la poesía es una forma de «experimentar» lo que creemos desconocer. Es, por tanto, una forma de conocimiento supradiscursivo. De un lado está el conocimiento abstracto; de otro, la experiencia de lo desconocido; de uno, el Dios de los teólogos, lejano, filosófico; de otro, el Dios de los místicos y poetas, sensible al corazón y a lo más profundo de nosotros. El conocimiento de la poesía es directo. Nos ofrece, aunque no llegue a definirlas, una comprensión cordial de las realidades invisibles. Tiene, por ello, acceso a dominios nunca antes logrados por la ontología. El poeta está dotado de una supervisión·» (p. 277)

40 Juan Ramón Jiménez, op. cit. en N. 3, aforismo número 2289

${ }^{41}$ C. S. Lewis, La experiencia de leer. Un ejercicio de crítica experimental, Barcelona, Alba, 2008, $4^{\mathrm{a}}$ ed., pp. 100-101. El ensayo se publicó por vez primera, en inglés, en 1961 
vieron en Madrid. Es más, se cartearon hasta la muerte de la esposa del poeta. Pues bien, Françoise escribió con absoluta sinceridad: «Tenía Juan Ramón el sentido de su superioridad ${ }^{42}$. Se reconocía a sí mismo como un gran poeta. Como uno de los grandes. Sin recato. Sin rubor. Porque, claro, no hay duda, era radicalmente cierto. En él había demasiado fuego $^{43}$. Así, no es de extrañar que, por ejemplo, hablando del prodigio de su Obra, del hecho -incuestionable para él- de ser una de las más grandes de la historia de la literatura, diga que «esto sólo significa haber nacido dotado para una obra así, como se nace rubio o se nace moreno, y en todo caso mi único mérito es mi amor a la poesía, que ha sido la pasión de toda mi vida ${ }^{44}$. Juan Ramón, insistimos, se sabe grande, se sabe genio. De ahí una de las razones de su obsesión por la muerte. Por su muerte. Porque su muerte no será una muerte cualquiera. Será la muerte de alguien muy valioso. De un yo inmenso que ya no podrá seguir creando belleza. Que ya no podrá sentir momentáneamente -éxtasis- la gloria del infinito. Ésta es la última razón de que le aterre la Muerte. Su muerte. Y la muerte de aquéllos a los que ama. Que le recuerda muy cerca, muy cerca, la suya. Por ejemplo: su madre, Mamá Pura, María de la Purificación Mantecón López-Parejo, morirá en 1928; pues bien, en el poema 14 -sin título- de la segunda parte de Ellos, dedicado a su madre vieja, habla de la muerte como de «el veneno que tiene la virtud fea/de hacer rápido lo eterno». ¡Qué maravilla!:

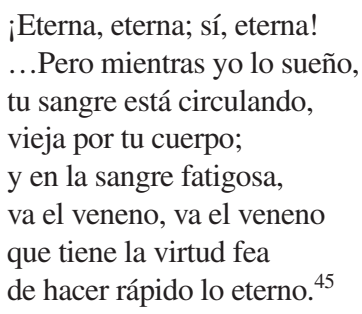

Hacer rápido lo eterno... Por amor de la belleza Juan Ramón siente la vida como eterna. El esteta sabe sentir la eternidad. Aquí y ahora. La muerte no es sólo la cesación, la liquidación de todo eso. Ni más ni menos. Sino que, además, su presencia constante, su recordatorio constante hace «rápida» la sensación de eternidad que ha logrado alcanzar en vida. Y éste es el insufrible padecimiento de Juan Ramón. La muerte es el veneno que atenúa -que hace «rápido»- su capacidad de belleza, que es su capacidad de eternidad en vida. Juan Ramón no desea otra cosa que belleza. Y la muerte es el impedimento. «Es verdad que yo soy muy pasivo, muy esclavo ante la belleza. Me dejo invadir plenamente, sin interés alguno que no sea gozar, perdido, en ella» ${ }^{46}$. La muerte es el impedimento de esta dichosa esclavitud.

\footnotetext{
${ }^{42}$ Françoise Pechère, «Historia de una amistad» en Aurora de Albornoz (Ed.), op. cit. en N. 15, p. 43

${ }^{43}$ Parafraseamos, claro, la imponente frase de Elías Canetti: «No puedo ser modesto; en mí hay demasiado fuego» (Elías Canetti, La provincia del hombre. Carnet de notas 1942-1972, Madrid, Taurus, 1982, p. 21)

${ }^{44}$ Son palabras de Juan Ramón en 1931 tal como las recuerda Juan Guerrero Ruiz filtradas por su memoria tras unas horas de conversación. En Juan Guerrero Ruiz, Juan Ramón de viva voz (texto completo) - Volumen I (19131931), Valencia, Pre-textos/Museo Ramón Gaya, 1998 (prólogo y notas de Manuel Ruiz-Funes Fernández), p. 267

${ }^{45}$ Juan Ramón Jiménez, op. cit. en N. 20, p. 102

${ }^{46}$ Así dice en Olvidos de Granada, en carta a Isabel García Lorca del 19 de julio de 1924. En Juan Ramón Jiménez, Olvidos de Granada (1924-1928) / Sevilla, Madrid, Visor, 2008, p. 92
} 
La muerte podría ser el tóxico irreversible, el insuperable accidente que le hiciera perder la certeza que había descubierto: la inmanencia, que dios, que el infinito está también, y principalmente, en su interior. Que yo, Juan Ramón, soy portador eminente de infinito:

Yo estoy seguro de que en este mundo en que vivimos y morimos hay un más allá en inmanencia, un más allá moral, y que el poeta es el que puede comprender, contener y esperar esa inmanencia sin límites. ${ }^{47}$

Juan Ramón estuvo siempre en perpetuo estado de vigilia poética, de predisposición, al acecho de su interior. Tuvo siempre la rama preparada para la rosa justa ${ }^{48}$. Dedicó toda su vida, la pasó toda, buscando en sus entrañas su sustento ${ }^{49}$. Y lo encontró dentro de sí mismo, en efecto. Miguel de Unamuno en Cómo se hace una novela nos recuerda que

Hugo de San Víctor, el místico del siglo XII, decía que subir a Dios era entrarse en sí mismo y no sólo entrar en sí, sino pasarse de sí mismo, en lo de más adentro -IN INTIMIS ETIAM SEIPSUM TRANSIRE- de cierto inefable modo, y que lo más íntimo es lo más cercano, lo supremo y lo eterno. ${ }^{50}$

La genialidad de Juan Ramón, ya lo sabemos, estriba no sólo en saber entrarse en lo de más adentro de sí mismo sino en saber decirlo, claro. Saber decirlo claro. Vencer lo inefable. La genialidad de Juan Ramón -hija de la belleza- reside en concebir a dios en su interior, como el Maestro Eckhart, y, amándolo, penetrarlo. En efecto, el Maestro Eckhart escribió: «Dios y yo somos uno. Por el conocimiento concibo a Dios en mi interior; por el amor, por el contrario, penetro en Dios» ${ }^{51}$. También escribió:

Todas las criaturas quieren decir a Dios en sus obras; todas hablan tan apasionadamente como pueden, pero no lo pueden decir. Tanto si quieren como si no quieren, les guste o no: todas quieren decir a Dios y, sin embargo, Él permanece inefable. ${ }^{52}$

La maravilla juanramoniana, insistimos, es que sí lo supo, sí lo pudo decir. Toda su Obra es un continuo decirlo. Toda su vida pasó diciendo lo que los demás no sabían decir. Toda su vida la pasó haciéndonos ese inapreciable regalo: saber el absoluto y saber contarlo en la palabra justa. Cerca del final de sus años, en 1953, en conversación con Ricardo Gullón, lo resumía así: «¿Qué es Dios sino un temblor que tenemos dentro, una inmanencia de lo inefable? $\gg^{53}$ Juan Ramón, pues, fue ese hombre

\footnotetext{
${ }^{47}$ Juan Ramón Jiménez, Estética y ética estética, Madrid, Aguilar, 1967 (ed. de Francisco Garfias), p. 95

48 «Siempre tienes la rama preparada / para la rosa justa» es el comienzo del bellísimo soneto «A mi alma» de los Sonetos espirituales. En Juan Ramón Jiménez, Pájinas escojidas. Verso, Madrid, Gredos, 1981, $3^{\mathrm{a}}$ reimpr. (selección y nota preliminar de Ricardo Gullón), p. 122

${ }^{49}$ «Fabricaré en mi sombra la alborada, / mi lira guardaré del vano viento, / buscaré en mis entrañas mi sustento... / Mas ¡ay!, ¿y si esta paz no fuera nada?» Es el segundo cuarteto del no menos bello soneto «Nada», también de los Sonetos espirituales. En Ibídem, p. 119

${ }^{50}$ Miguel de Unamuno, La Tía Tula / Cómo se hace una novela, Estella, Salvat, 1982, p. 182

${ }^{51}$ Maestro Eckhart, op. cit. en N. 24, p. 55

${ }^{52}$ Ibídem, pp. 83-84

${ }^{53}$ Recogido por Ricardo Gullón en Conversaciones con Juan Ramón, Madrid, Taurus, 1958, p. 108
} 
de arriba, tanto por su vida cuanto por su palabra -es lo mismo-, que estuvo en permanente devaneo divino, en permanente estado de humanísima divinidad. Fue ese hombre alto que hizo ciertas, muy ciertas, aquellas palabras de Cioran: «Aunque exteriormente tengamos todo lo propio del animal y nada de la divinidad, la teología explica mejor nuestro estado que la zoología ${ }^{54}$.

El logro definitivo de Juan Ramón es que, siempre en comunicación su alma (pura) con la pura belleza, derrotó a la muerte. Se permanece en su palabra. Si hacemos caso a Carlos Castilla del Pino - «el hombre está hecho para crear» ${ }^{55}$-, Juan Ramón es el hombre por antonomasia. La tragedia hubiera sido que un hombre así hubiera muerto completamente. Que hubiera muerto como los demás un hombre como Juan Ramón, un hombre que creó tantos versos inmortales, un hombre que pudo el infinito. Como no podía ser de otra manera, se sobrevivió en la palabra bella. En sus palabras. Como dice Ana Recio Mir: «El autor se sabe consciente de su finitud, sabe que la muerte es el final de toda la existencia, pero acepta gozoso su destino porque ha conseguido transmutar su ser en obra poética» ${ }^{56}$.

Como Horacio, como su contemporáneo y amigo Unamuno -ambos sufrieron de lo mismo-, «Juan Ramón creía firmemente que mediante la realización de su Obra se iba a eternizar en la memoria de las sucesivas generaciones humanas ${ }^{57}$. En realidad es mucho más que esto que propone Arturo del Villar en lo que creía Juan Ramón. Creía en algo muchísimo más grande que el erostratismo, que una mera vida de la fama. En el momento abismal de crear la Belleza, o de recrearla leyéndola -leyéndose-, es cuando era infinito; y en la misma Belleza creada se permanecía infinitamente. El infinito se despliega, se exhibe ostensible en la propia creación y en el absoluto creado. Por eso, en ese libro imprescindible que es La Muerte, escrito entre 1918 y 1924 aunque permanentemente reelaborado, Juan Ramón se permite decir versos como éstos: «Cuando tú quieras, muerte. / Te he vencido. / ¿Qué poquito / puedes ya contra mí!» ${ }^{58}$. O como éstos: «Nada me importa esta muerte / que es la caída del cuerpo. / No me moriré al morirme / de esta manera de aquí» ${ }^{59}$. O como éstos: «iQue, con la muerte, sea yo / lo mismo que la campanilla azul; / que, al cerrarse, a la tarde, / deja fuera de sí todo su aroma, / para que se lo lleve a donde quiera el aire! ${ }^{60} \mathrm{O}$ como este verso grande de «El pajarito verde»: «iQué grato el irse, cuando se queda uno en todo!» ${ }^{61}$

Juan Ramón, en su vida finita, acertó a saber el infinito. A asegurarse de él. Porque se atrevió a vivir una vida de calidad. Porque se atrevió a dedicar su tiempo a lo que le merecía las venas: «La vida no es más que calidad, ¿y no será lo divino solamente la ca-

\footnotetext{
${ }^{54}$ E. M. Cioran, La caída en el tiempo, Barcelona, Tusquets, 2003, $3^{\text {a }}$ ed., p. 25

${ }^{55}$ Carlos Castilla del Pino, de su conferencia de 1968 «Estructura social y frustración» en El humanismo «imposible». Estructura social y frustración, Madrid, Ciencia Nueva, 1970, p. 53

${ }^{56}$ Ana Recio Mir, «El último Juan Ramón» en el Suplemento conmemorativo de los cincuenta años de la muerte del poeta titulado «JRJ. La inmortalidad del genio» (El Correo de Andalucía, 29 de mayo de 2008), p. 20

${ }^{57}$ Arturo del Villar, «Las cosas de Juan Ramón» en Letras de Deusto, № 116 (Vol. 37), julio-septiembre 2007, homenaje a Juan ramón Jiménez II, p. 110

${ }^{58}$ Juan Ramón Jiménez, La Muerte, Barcelona, Seix Barral, 1999 (edición y estudio preliminar de Diego Martínez Torrón), p. 75

${ }^{59}$ Ibídem, p. 77

${ }^{60}$ Ibídem, p. 136

${ }^{61}$ Ibídem, p. 152
} 
lidad mayor?» ${ }^{62}$. En Seis propuestas para el próximo milenio, al final de sus días, Italo Calvino se planteaba:

...una sola vida, del nacimiento a la muerte, puede contener sólo una cantidad finita de información: ¿cómo pueden lo imaginario individual y la experiencia individual extenderse más allá de ese límite? ${ }^{63}$

Juan Ramón pudo por medio de la Belleza. Probablemente el único camino. Probablemente fue él uno de los pocos que supo recorrerlo.

${ }^{62}$ Juan Ramón Jiménez, Guerra en España (1936-1953), Barcelona, Seix Barral, 1985 (introducción, organización y notas de Ángel Crespo), p. 286

${ }^{63}$ Italo Calvino, Seis propuestas para el próximo milenio, Madrid, Siruela, 2007, $7^{\text {a }}$ ed., p. 103. Ya en la página 27, hablando del averroísmo, escribe Calvino que «la muerte corporal es vencida por quien se eleva a la contemplación universal a través de la especulación del intelecto»... 
